\title{
Acute Esophageal Necrosis: About A New Clinical Case
}

S. Roudi ${ }^{1 *}$, M. A. Lkousse ${ }^{1}$, J. Rizkou ${ }^{1}$, F. Aboutarik ${ }^{1}$, A. AitErrami ${ }^{1}$, S. Oubaha ${ }^{2}$, Z. Samlani ${ }^{1}$, K. Krati ${ }^{1}$

${ }^{1}$ Department of Hepato-Gastro-Enterology, Arrazi Hospital, Mohammed VI University Hospital Center, Marrakech 40000, Morocco

${ }^{2}$ Department of Physiology, Faculty of Medicine, Cadi Ayyad University, Marrakech 40000, Morocco

DOI: $10.36347 /$ sjams.2020.v08i07.023

| Received: 13.07.2020 | Accepted: 20.07.2020 | Published: 24.07.2020

*Corresponding author: S. Roudi

\section{Abstract}

Acute esophageal necrosis is a rare condition. The diagnosis is easily made by an upper digestive endoscopy which shows a black esophagus appearance. The etiology is not clearly established but seems to be multifactorial. The treatment of acute necrotizing esophagitis is primarily medical. We report a case of acute necrotizing esophagitis revealed by upper gastrointestinal bleeding.

Keywords: Acute necrotizing esophagitis, gastrointestinal bleeding, endoscopy, black esophagus.

Copyright @ 2020: This is an open-access article distributed under the terms of the Creative Commons Attribution license which permits unrestricted use, distribution, and reproduction in any medium for non-commercial use (NonCommercial, or CC-BY-NC) provided the original author and source are credited.

\section{INTRODUCTION}

Acute necrotizing esophagitis is a severe form of acute esophagitis in which, on endoscopy, the esophagus is dark and black in color ("black esophagus"). This appearance corresponds histologically to mucous necrosis. It is an infrequent, but largely underestimated and poorly understood entity. We report a new observation of a case of acute necrotizing esophagitis revealed by upper gastrointestinal bleeding.

\section{CASE REPORT}

A 42-year-old patient, type II diabetic on insulin therapy for 5 years unbalanced, admitted to the emergency room for hematemesisof great abundance, since 3 days before admission with hemodynamic instability. The history did not note any known drug intake or caustic products. The examination found a patient with cardio circulatory failure (blood pressure $90 / 50 \mathrm{~mm} \mathrm{Hg}$, heart rate 130 beats per minute) for whom he was taken care of in the intensive care unit. The blood tests showed a microcytic hypochromic anemia with an hemoglobin at $6.8 \mathrm{~g} / \mathrm{dl}$, an acute renal failure, a hyperglycemia at $3 \mathrm{~g} / \mathrm{L}$, a serum level of $\mathrm{C}$ reactive protein at $118 \mathrm{mg} / \mathrm{l}$. After the patient was stabilizied, an upper endoscopic exploration was made showing blackesophagus aspect of the lower third of the esophaguswith an erythematous, ulcerated appearance covered with a whitish coating of 1 / 3 middle of the esophagus, as shown in the picture below.
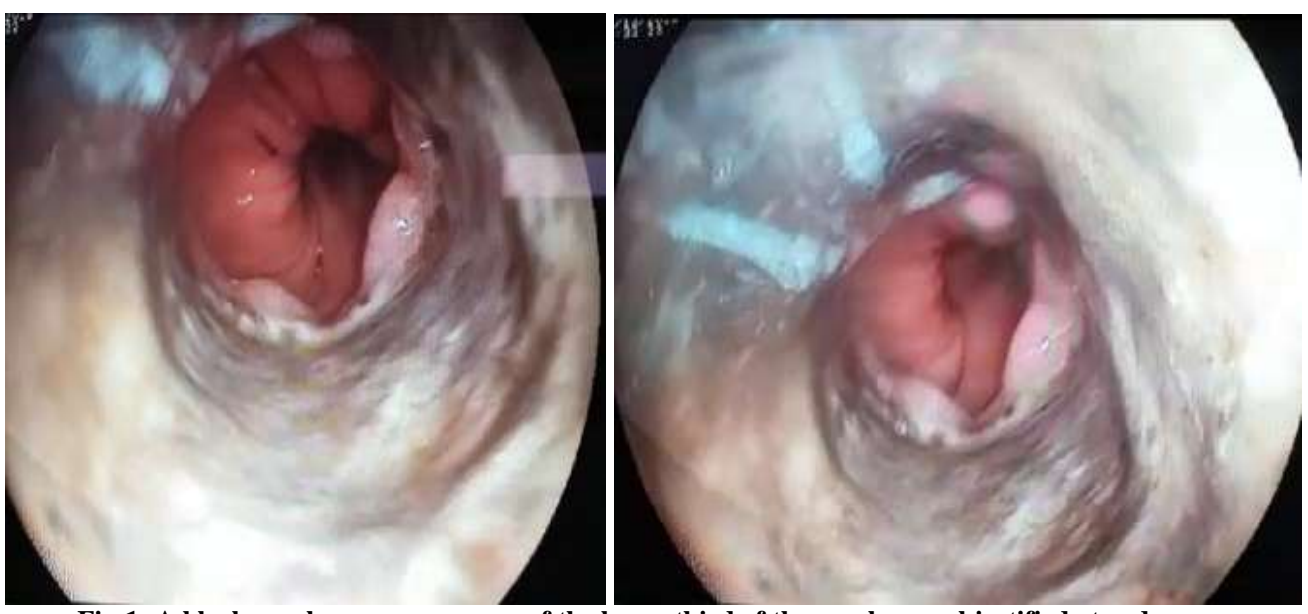

Fig-1: A black esophagus appearance of the lower third of the esophagus objectified at endoscopy 
The evolution was marked by the death of the patient following a cardio respiratory arrest despite cardiopulmonary resuscitation measures.

\section{DISCUSSION}

Endoscopic description of "a black esophagus" is rare. It was first described in 1990 by Goldenberg et al., [1]. It most often corresponds to ischemic necrosis but other factors have been accused, in particular infectious, traumatic or toxic. The arterial vascular supply of the esophagus is characterized with rich anastomotic networks explaining the rarity of lesions of ischemic origin. The first cases have been described following esogastric surgery or after aortic dissection [2].

Acute necrotizing esophagitis affects patients of various ages, between 21 to 89 years old (median of 65 years) with male predominance [3]. Its pathophysiology is not clearly established and appears to be multifactorial. An ischemic origin is frequently mentioned associated to diabetes in $24 \%$ of cases, high blood pressure or cancer in $20 \%$ of cases, excessive alcohol consumption in $10 \%$ of cases or coronary artery disease in $9 \%$ of cases [3]. Gastroesophageal reflux (found in $40 \%$ of cases) has also been implicated. Indeed, some authors postulate that esophageal necrosis is related to a direct toxic effect of gastric fluid on the mucosa [2]. In addition to gastroesophageal reflux, gastric obstruction would favor the occurrence of acute necrotizing esophagitis due to stasis of the gastric fluid. Viral infections have been proposed as a possible cause: among 31 cases described in the literature, two occurred in the context of herpes virus infection [4]. Other authors suggest an iatrogenic cause such as taking NonSteroidal Anti-Inflammatory Drugsor antibiotics (in particular ampicillin, gentamicin and cefoxitime) [2]. In one published case, acute necrotizing esophagitis occurred in a context of severe hypothermia [5]. In our case, the only etiopathogenic factor suggested is the patient's diabetic decompensation.

The clinical presentation combines hematemesis with melena, epigastric abdominal pain, nausea, vomiting, dysphagia, fever or syncope can be observed [6]. In our case, the patient presented a table of hematemesis without any other associated signs.

The diagnosis of acute necrotizing esophagitis is made by upper digestive endoscopy. Necrosis is almost always circumferential. It can be extended across the esophagus to the gastroesophageal junction. At the junction, there is a brutal transition zone from which the mucosa returns to its normal appearance.

Biopsy is possible but not essential for diagnosis, it must be careful and performed depending on what we found in endoscopic exploration. When performed, it shows severe necrosis of the mucosa and submucosa. Inflammation and partial destruction of the adjacent muscularis may occasionally be observed, blood vessels may be thrombosed, however this necrosis is rarely transmural unlike caustic necrosis [7].

When we find this aspect of "black esophagus", it is essential to determine its origin. The first diagnosis to be discussed is the ingestion of caustic substances [8], but the context, the history, the association with oropharyngeal lesions most often allow the diagnosis to be made. Rarer pathologies should also be considered: esophageal "melanosis", primary malignant melanoma of the esophagus, pseudo melanosis, acanthosis nigricans, trauma or a history of radiotherapy [9]. The first two possibilities have typical endoscopic aspects and the diagnosis is confirmed by histology [10]. Pseudo-melanosis is linked to deposits of lipofuscin (ceroid) in smooth muscle cells, carbon or other "pigments" tattooing the esophagus [11]. Acanthosis nigricans is a focal lesion associated with skin lesions and sometimes used as part of paraneoplastic manifestations [12].

Possible complications of this necrosis are a secondary bacterial infection, perforation of the esophagus, mediastinitis, or severe sepsis. Scarring can be done by progressing to stenosis in $10 \%$ of cases.

The mortality specific to this entity is evaluated at $6 \%$, but reaches $32 \%$ if we consider the other associated pathologies [8].

The prognosis can be severe during esophageal perforations with the risk of mediastinitis. Apart from these circumstances, the evolution is often favorable.

The therapeutic management of "acute ischemia" of the esophagus is multidisciplinary. The initial phase includes resuscitation of the shock and multi-visceral failure associated with resting the digestive tract and total parenteral nutrition. Early endoscopic control is recommended between two and seven days to assess the evolution of the lesions and decide on refeeding. The prognosis of these black esophaguses is reputed to be poor, but the analysis of the reported cases actually shows a favorable local evolution with regression of the lesions in one in two cases. Stenosis was observed in two cases. The deaths seem more related to the ethiology and comorbidities rather than to esophageal lesions [13].

\section{CONCLUSION}

Acute necrotizing esophagitis is a rare entity, with a physiopathology that remains poorly understood and whose positive diagnosis is easily made by an upper digestive endoscopy.

Serious complications such as perforation and mediastinitis can occur which can be life-threatening all the more if you have associated comorbidities. 


\section{REFERENCES}

1. Goldenberg SP, Wain SL, Marignani P. Acute necrotizing esophagitis. Gastroenterology. 1990;98:493-6.

2. Geller A, Aguilar H, Burgart L, Gostout CJ. The black esophagus. Am J Gastroenterol. 1995; 90: 2210-2.

3. Gurvits G, Shapsis A, Lau N, Gualtieri N, Robilotti JG. Acueteesophagealnecrosis : a rare syndrome. J Gastro Enteral. 2010; 42:29-38.

4. Cattan P, Cuillerier E, Cellier C, Landi F, Dusoleil A, Barbier JP. Blackoesophagus associated with herpes esophagitis. Gastrointest Endosc. 1999;49:103-5.

5. Cadot $\mathrm{P}$, Duverger V, Imperato M, Lapprand M, Vergos M. Esophage noir associé à une hypothermie. Ann Chir. 2001;126:903-5.

6. Hermet A. Nécrose aigue de l'œsophage. Rev Med Interne. 2013.

7. Long JD, Orlando RC. Gastrointestinal and liver disease. 8th ed. Philadelphia Anatomy, histology, embryology, and developmental anomalies of the esophagus. 841-53.

8. Moreto M, Ojembarrena E, Zaballa M, Tanago JG, Ibanez S. Idiopathic acute oesophageal necrosis: not necessarily a terminal event. Endoscopy. 1993;25:534-8.

9. Pelletier. Annales Françaises d'Anesthésie et de Réanimation 23 (2004) 601-603

10. Guernazi A, Rili M, Fritsch S, Turki C, Benchaïb $\mathrm{N}$, de Kerviler E. Mélonome malin primitif de l'œsophage. Ann Chir, 2000; 125: 985-8

11. Khan HA. Coal dust deposition: rare cause of black esophagus. Am J Gastroenterol. 1996; 91: 225-6.

12. Minocha A, Richards RJ. The black esophagus. Am J Gastroenterol. 1996; 91: 1470-1.

13. Langle C, Cadiot G, Calvat S. Deux cas d'œsophage noir découverts lors d'une acidocétose diabétique grave. Gastroentérol Clin Biol. 1994; 18: 176-7. 